\title{
PERCORRER O ESPAÇO: A IMAGEM DO TERRITÓRIO NA PINTURA DE PAISAGENS
}

- LENICE LIRA - UERJ

RESUMO: ESTE TEXTO ABORDA AS QUESTÕES RELACIONADAS À REPRESENTAÇÃO DA PAISAGEM PELA PINTURA COMO EXPERIÊNCIA MEDIATIZADA DAS REALIDADES ESPACIAIS. A PAISAGEM SURGE COMO PERCEPC̦̃̃O DO TERRITÓRIO, INAUGURANDO UM NOVO MODO DE DAR FORMA E DE INTERPRETAÇÃO DO MUNDO: UM OUTRO OLHAR. A EXPERIÊNCIA PAISAGÍSTICA REMETE À APREENSÃO DO MUNDO ENQUANTO CONSTRUÇÃO CULTURAL. DESTE MODO, A VISÃO DO TERRITÓRIO ESTÁ INTRINSECAMENTE RELACIONADA A UMA ORGANIZAÇÃO DO VISÍVEL, A QUAL É ATRIBUÍDA UMA CERTA SIGNIFICAÇ̃̃O. NESSE CONTEXTO, FOI DEMARCADO UM PERCURSO DA EXPERIÊNCIA DA PAISAGEM NA ARTE E NA GEOGRAFIA, QUE PERMITE A COMPREENSÃO DO MUNDO VISÍVEL EM SUA FORMA VISUAL E NO ÂMBITO DA LINGUAGEM. TAIS QUESTIONAMENTOS E COLOCAÇ̃̃ES DIALOGAM COM AS PINTURAS DE LEANDRO JOAQUIM, ARTISTA FLUMINENSE DO SÉCULO XVIII.

PALAVRAS-CHAVE: PAISAGEM, REPRESENTAÇ̃̃ES, TERRITÓRIO, IMAGEM, LEANDRO JOAQUIM.

Não é o sujeito que explica a essência, é, antes, a essência que implica, se envolve, se enrola no sujeito. Mais ainda: enrolando-se sobre si mesma ela constitui a subjetividade.

Não são os indivíduos que constituem o mundo, mas os mundos envolvidos, as essências, que constituem os indivíduos: 'Esses mundos que são os indivíduos e que sem a arte jamais conheceríamos'. Gilles Deleuzel

Nos anos de 1970, a geografia Nesse novo cenário, as representações cultural vivencia um momento de inovação. assumem uma relevância como objeto de As discussões sobre a paisagem são análise e de interpretação das variadas retomadas a partir de novas abordagens. 
realidades espaciais, em especial nos estudos culturais sobre paisagem.

A geografia cultural praticada até os anos 1970 apresentava um forte vínculo com a etnografia. Desse modo, os estudos das realidades culturais, de matrizes alemã, francesa e norte-americana, detinham-se na análise dos utensílios, das técnicas e das transformações da paisagem. Os processos culturais eram analisados, grosso modo, sob a tutela dos aspectos materiais da cultura e o seu caráter simbólico, até então, era negligenciado.

Com a renovação da geografia cultural, pós 1970, surgem novas abordagens sobre a dimensão cultural do espaço. Nesse contexto, as representações tornam-se objeto de análise e de interpretação dos fenômenos culturais no espaço, em objeto de interpretação do mundo.

As representações operam no campo do objeto ausente que se presentifica ao ser apresentado ao espírito.

Até o século XIX, a representação era tomada como fundamento geral de todas as ordens possíveis, como uma verdade. No início desse século, há uma mudança na teoria da representação e da linguagem. Ocorre o abandono da representação mimética, enquanto as coisas reclamam para si seu movimento, o princípio de inteligibilidade (FOUCAULT, 2007).
É neste sentido, que conferimos à representação o campo da ordem da coexistência, no que concerne ao espaço, e da sucessão, no que diz respeito ao tempo. Ela dá visibilidade às organizações espaciais e sucessões de tempo que constituem a existência do mundo natural e do mundo social. Dessa maneira, o ato de representar não significa tão somente a substituição de objetos ausentes, mas também a sua apresentação de modo diferente, que torna possível a sua suspensão e, consequentemente, a inauguração do reflexivo de um modo de apreender e ver o mundo; isso possibilita a sua ressignificação em outros contextos ou realidades, que podem ser aqueles da pintura, da música, da dança, do território.

Este texto constitui, portanto, um esforço de colocar em questão o lugar das representações artísticas na construção de uma determinada localidade. A abordagem do tema conduz até as pinturas de paisagem de Leandro Joaquim, no século XVIII. Trazer essa discussão para a geografia implica $\circ$ reconhecimento de que as obras de arte constituem significados corporificados, que atuam na construção de um imaginário que pode intervir na produção do real, no ordenamento do espaço, ressignificando-o ao colocar em jogo a possibilidade de novas experiências e práticas sociais. É nessa 
direção que caminham as indagações a propósito da pintura enquanto um mecanismo de intervenção no espaço, que participa da construção de um olhar sobre as localidades, que elege e qualifica os elementos de identidade territorial

\section{PAISAGEAR: O ESPAÇO GEOGRÁFICO ARTIALISADO}

A pintura constitui uma imagem produzida por um sujeito individual - o comunicação de massa. A tirania da imersão pictórica dos espectadores resulta em envolvimento emocional descontrolado sem a devida distância crítica da mensagem pictórica (BUDDEMEIER, 1993).

A pintura parece encontrar-se na fronteira entre a manipulação opressora, persuasiva, convidativa e, muitas vezes, dócil, e a libertação dessa manipulação. As relações entre o visível e o invisível, na pintura aparecem intricadas. Para iludir, convencer, é necessário competência e faz parte desta antecipar com precisão a moldura, o olhar do observador, as circunstâncias da recepção da imagem, os códigos em jogo. O ilusionismo tem como principal função, e talvez única, fazer desaparecer a fronteira entre $\circ$ real e o imaginário. A leitura da imagem não se faz imediatamente. É resultado de um processo, onde intervêm não só as mediações que artista, e, num primeiro momento, é de caráter contemplativo, para capturar o imaginário do observador, uma vez que é próprio do Eu se projetar nas imagens em que se espelha.

As imagens são vistas sob um olhar de desconfiança, tendo sempre um tom pejorativo em quase todos os discursos sobre os meios

de

estão na esfera do olhar que produz a imagem, mas também aquelas presentes na esfera do olhar que as recebe. Pois, este não é inerte, ele participa do jogo.

Há vários elementos e operações comuns entre o processo pictórico e o olho humano que favorecem uma identificação do meu olhar com o do pintor, resultando daí um sentimento da presença do mundo na tela, simultâneo ao conhecimento de sua ausência, uma vez que se trata de imagens e não das coisas mesmas. A imagem recebida compõe um mundo evidenciado por um olhar exterior a ele, que the organiza uma aparência das coisas, estabelecendo uma ponte e um obstáculo entre o espectador e o mundo. A produção do acontecimento que the é permitido ver e o seu próprio olhar são dois momentos distintos e separados por todo um processo. No ato de pintar estão implicados uma copresença, um compromisso, um risco, 
um prazer e um poder de quem tem a possibilidade e escolhe pintar.

O espectador contempla uma imagem sem ter participado de sua produção, sem escolher ângulo, distância, sem definir uma perspectiva própria para a observação ou pontos de vista. Ao contrário das situações da vida em que se está presente ao acontecimento, no quadro não se tem o trabalho de buscar diferentes posições para observar o mundo; tudo se faz em nome do espectador, antes de seu olhar intervir, num processo que evidencia o que talvez de outro modo seria, para ele, de difícil acesso. $\bigcirc$ espectador tem seus privilégios. Por outro lado, algo the é negado: a escolha. Pode-se escolher a emoção que se espera sentir, sem, no entanto, escolher o enredo a ser trilhado.

Vê-se tudo de perto, e bem visto, detalhado na tela, de modo a surpreender o curso dos acontecimentos, dos gestos suspensos. $\bigcirc$ usufruto desse olhar privilegiado, não a sua análise, é algo que a pintura nos tem garantido, propiciando esta condição prazerosa de ver o mundo e estar a salvo, ocupar o centro sem assumir encargos. Estar presente, sem participar dele. $\mathrm{Na}$ ficção pictórica, junto com a superfície revestida de tintas, o espectador está em toda parte e em nenhum lugar; em todos os cantos, sem preencher espaços, sem ter presença reconhecida. O olhar da pintura é um olhar sem corpo. Identificado com este olhar, o espectador tem o prazer do olhar que não está situado.

Ao narrar essa estória, a pintura faz fluir as ações, no espaço e no tempo, tornando o mundo apresentável aos olhos do público. Em seu tornar visível, a mediação do olhar pictórico otimiza o efeito da ficção. A ilusão se apresenta tal e qual o real, fazendo com que haja uma identificação dos acontecimentos representados com os da vida, identificação do espectador com a personagem e a paisagem. É nesse processo que ocorre a captura do olhar e a instituição de uma intenção, fazendo do espectador prisioneiro da mensagem, pois a representação, o olhar sem corpo cria, na tela, um mundo abstrato, de sentido fechado, pré-julgado e organizado por ela.

Mas, também, a pintura permite que haja, ou melhor, evidencia a distância entre o real e o imaginário. Na criação de uma encenação, ela nos mostra nosso lugar, o não lugar, ou se preferirem, o estar ao lado, à margem do enredo, no belvedere ou no espaço do museu. Somos apresentados ao mundo retratado e com isto apreendemos o seu significado e o seu lugar, como ficção ou ilusão. A consciência desse fato, meio que óbvia, que toda obra de arte, nos liberta da necessidade de apreender sua mensagem. E 
faz com que vejamos mais claramente a mobilidade das construções imaginárias, e mesmo, que são construções.

A pintura é evidentemente um dos fabricantes de imagens. O olhar não é inocente. Toda leitura de imagem é produção de um ponto de vista. O olhar fabricado é uma constante oferta de pontos de vista. Observar com este olhar fabricado, o mundo, mas também colocá-lo em foco, recusando a condição de total identificação com o aparato, permite encontrar nos significantes pictóricos essa falsa homogeneidade cultural, ou seja, os signos, temas e símbolos que fazem parte do universo pictórico não podem ser reduzidos a um mesmo denominador comum cultural e contextual.

A pintura, em particular, foi responsável pela elaboração de um novo espaço, que advém da invenção da perspectiva, que contribui para a inscrição da paisagem na tela. Contudo, isso não é o suficiente para justificar a invenção da paisagem. O marco da invenção desse objeto-ideia é forjado quando um outro olhar

exige a atenção para esse tema. Assim, decidiu-se pelo suporte das discussões teórico-conceituais já concretizadas no cenário francês. Com esse propósito foram escolhidos três autores, que apresentam uma é modelado: distante, panorâmico; que é capaz de apreender o mundo natural através de fragmentos. Roger ressalta que a paisagem é uma construção de citadinos, pois eles possuem o distanciamento em relação à natureza, proporcionando uma visão panorâmica dos lugares; diferente dos campesinos, que estão inseridos na natureza, cujo olhar é baixo, muito próximo ao solo, aos quais foge a visão das lonjuras.

Percorrer O espaço: a imagem do território na PAISAGEM

A origem ou a invenção da paisagem foi tema de várias pesquisas, tanto no campo da arte como no da ciência. Tais pesquisas foram desenvolvidas, principalmente, na França e na Inglaterra. No Brasil, a delimitação dos começos de uma paisagem brasileira ou local foi pouco explorada. As pesquisas que se apropriaram desse tema, de modo geral, limitam-se ao campo da arte; os demais saberes dedicaram-se muito pouco às reflexões sobre essa questão. Desse modo, a demarcação dos começos da paisagem carioca

perspectiva comum relacionada à paisagem: a ideia da paisagem como construção cultural. São eles: Augustin Berque, geógrafo, que possui uma vasta produção acadêmica dedicada ao estudo da paisagem; Alain 
Roger e Anne Cauquelin, críticos de arte e filósofos, que elaboram análises importantes sobre a paisagem. As reflexões feitas por esses autores permitem pensar a paisagem carioca e, então, delimitar uma possível origem - o início de uma estética paisagística ou da apreciação estética da natureza na cidade do Rio de Janeiro. Nesse contexto, a cidade carioca apresenta dois marcos importantes: as pinturas de paisagem de Leandro Joaquim e a construção do Passeio Público do Rio de Janeiro, no século XVIII.

Anne Cauquelin, em $A$ invenção $d a$ paisagem (2007), mostra o pensamento e a construção da paisagem como um equivalente da natureza figurada, que deu origem a nossas categorias cognitivas e a nossas percepções visuais do espaço. No decorrer de seu texto essa ideia de paisagem, que, inicialmente, é percebida como um dado natural, vai sendo desconstruída, fazendo aparecer $\bigcirc$ seu caráter de artifício. Para tal, a autora traça o itinerário de reconstrução de sua gênese, identificada como um possível começo da paisagem.

Esse itinerário, que se estende do mundo grego à Renascença, circunscreve a aproximação e distância dos povos que trataram a paisagem em sua relação com o originário. Para Cauquelin, esse originário seria formado por milhares de dobras e de memórias, que possivelmente se constituíram enquanto "fundo", à margem no processo de constituição da paisagem. A proposição de Cauquelin é que desdobrar essas dobras significa criticar a ideia de que a paisagem é idêntica à natureza. E a autora prossegue afirmando que

a constituição da paisagem em natureza foi algo que teve longos séculos de preparação. E tal forma simbólica, atuante em tudo o que se refere ao espetáculo da natureza, não é fácil de analisar: ela só se deixa surpreender em pequenos passos, prudentes. Mal creríamos ser a paisagem mero artifício.

Essa retrospectiva histórica é importante, visto que permite inteirar-se das condições que tornaram possível a aparição da paisagem no Ocidente. Dessa maneira, torna-se incontornável a decomposição dos elementos, que formam as condições de possibilidade da edificação da paisagem. A história dessa edificação é comparada, pela filósofa, a uma floresta de símbolos, em que cada elemento precisa ser identificado e decifrado em sua relação marginal e direta com a paisagem. 
Neste sentido, Cauquelin reconhece rastros da paisagem, mas não a paisagem enquanto tal, desde o mundo grego até o Renascimento, quando, de fato, convergem as suas condições de afirmação.

No mundo grego, as descrições de "lugares" tinham o propósito de ilustrar as condições materiais do evento, que poderia ser uma guerra, uma expedição, uma lenda. Estas estão submetidas ao evento. O lugar não é protagonista. Ele é o palco, ou o cenário, onde os eventos se desenvolvem. Estes valem por si mesmos. Assim, nas descrições de Heródoto ou Xenofontes não encontramos paisagens, mas o suporte material dos eventos, os seus invólucros, conteúdos que são emoldurados, limitados, por formas.

Outro aspecto que justifica a ausência da paisagem entre os gregos é a visão integrada da natureza. Homens e natureza formam um único corpo. A paisagem implica um distanciamento em relação à natureza, para que assim ela possa ser apreendida, contemplada, observada, experimentada, exteriorizada.

A paisagem remete à primazia da visão. Aí os lugares assumem o primeiro plano e a sua condição de protagonistas e de autonomia.
Dentre as asserções de Cauquelin vale ressaltar a relevância da perspectiva na constituição da paisagem. A perspectiva viabiliza e legitima a representação figurada da natureza, cujo meio de expressão é o quadro. A aparição dos elementos naturais, no quadro, teria despertado o interesse por todos os aspectos da Natureza. Tal realidade somente seria acessível por meio deste suporte. Contudo, a paisagem ganha uma autonomia para além do quadro, e se transforma em uma realidade totalmente autônoma. É nesse contexto que se pode reconhecer os níveis de incorporação da paisagem na pintura. De início, como mero adorno, limita-se ao fundo ou a uma parte da composição pictórica para, enfim, tornar-se o motivo da própria pintura e esquema de percepção do mundo, tributário da perspectiva. Estamos diante de a supremacia da visão, instaurada como horizonte de conhecimento e de verdade.

A paisagem, então, seria a manifestação da natureza, o aparecer simbólico dessa força infinita e violenta, que sob os véus do simbólico é domesticada, ordenada, tornando-se acessível ao homem. Contudo, essa grandeza e selvageria da natureza são mantidas à distância, mas não ignoradas. É justamente esse jogo de ocultação e de vir à luz da natureza que nos mantém próximos e distantes dela. Nessa 
posição, podemos dizê-la e transformá-la em imagem, capturando, assim, a sua essência.

Segundo Anne Cauquelin, a retórica entendida como todas as figuras de linguagem ou do discurso: metáforas, metonímias, sinedoque, entre outras - realiza a passagem da natureza selvagem para a paisagem civilização. Como exemplifica a filósofa (p. 133): "a floresta-natureza se

Para Cauquelin, o advento da paisagem deve-se a duas operações indispensáveis: o enquadramento e o jogo de transportes entre os quatro elementos de que a natureza se constitui para nós - água e areia, terra e céu. $O$ enquadramento assinala o momento em que ocorre a subtração de uma parte da visão ao olhar. Escolhe-se o melhor ângulo, ou ponto de vista, e a imagem é capturada e emoldurada. Ainda a respeito do enquadramento a autora lembra que

o enquadre exige o recuo, a distância certa. Tudo ver, claro, mas apenas aquilo que está no campo. E, ainda, o enquadramento inspira ordem, dá a regra dos primeiros planos e dos planos de fundo [...].

Porque a moldura corta e recorta, vence sozinha o infinito do mundo natural, faz recuar o excedente, a diversidade. $^{2}$ transforma em paisagem civilizada. Dois termos em um. Dois objetos em um".

A árvore é a floresta. A árvore podada é a floresta desprovida de qualquer traço de desordem. Tais afirmações nos permitem dizer que a composição paisagística elabora uma espécie de síntese da natureza, em que as partes representam uma totalidade.

Com efeito, o estabelecimento destas operações resultou na enunciação da paisagem. Somente, então, temos diante dos olhos uma paisagem que não estava ali antes da constituição de tais operações, que são consideradas figuras da artificialidade, que oferecem $\circ$ limite necessário para a sua constituição.

As primeiras aparições do artifício do enquadramento na pintura se dão com a presença da janela nos quadros, que ocupa uma parte da composição. A janela constitui a delimitação do exterior.

A paisagem evoca a presença da natureza. Ela existe, desde o início, enquanto vínculo com a natureza. Quando se fala, no mundo contemporâneo, no fim da paisagem, o que está em questão é o esquecimento do vínculo entre a humanidade e a natureza, expresso em suas paisagens. A destruição e degradação da natureza - marcadas pela 
substituição, cada vez mais acelerada, do mundo natural e por outro artificializado, por um meio técnico-científico-informacional, em que a natureza se reproduz em laboratório, na condição de artifício - demonstram o enfraquecimento desse vínculo.

gesto humano nas paisagens pode ser interpretado como uma marca da afirmação desse vínculo, harmônico ou conflituoso, desse acordo entre cultura e natureza.

A cultura permite apropriações distintas da natureza no decurso da história e das especificidades locais. Assim, a cultura renascentista propiciou uma apropriação singular da natureza, que envolve os processos de designação, significação e manipulação da mesma, figurada na forma simbólica paisagem. Tais processos resultam em outros, como, por exemplo, a formação das identidades territoriais. Com a invenção da paisagem, as sociedades e os indivíduos passam a reconhecer-se enquanto pertencentes a uma localidade, a um território. Esse reconhecimento se dá através da produção de imagens, por meio da exteriorização das subjetividades.

É possível afirmar, desse modo, que a paisagem inaugura a experiência e o olhar do e sobre o mundo. Já o ambiente, que é dado a ver a qualquer sociedade, não exige de nós o abandono de si e o repousar-se no outro, habitando-o. E neste caso significa habitar a Terra e reconhecer esse vínculo entre mundo e terra, que constitui o teor de nossa humanidade. São as paisagens e as obras de arte que nos permitem viver e expressar o sentido de uma existência que se realiza no espaço, no mundo, no exterior, com o mundo natural e construído. A arte exterioriza as relações pessoais com $\bigcirc$ mundo, que resultam em variadas manifestações artísticas. A paisagem é a manifestação de uma existência espacial. O existir não se restringe à condição espacial. O tempo é um fundamento de nossa existência na Terra. O fato de falarmos pouco dele deve-se à necessidade de dar visibilidade ao espaço como elemento constitutivo da realidade, da própria humanidade.

Arte, geografia e filosofia não constituem caminhos opostos da existência humana, mas itinerários distintos que no processo de interação e de interfecundação contribuem para uma compreensão e análise mais aprofundadas da paisagem e do sentido da existência humana inscrito na terra, na tela, no verbo, nas formas urbanas, nos vínculos sociais, que se limita às experiências (individuais e coletivas) do corpo no ambiente e às ilimitadas imagens que delas produzimos. 
A abordagem cultural das realidades geográficas é entendida por Augustin Berque (1983, p. 3) como "o estudo do sentido (global e unitário) que a sociedade atribui a sua relação com o espaço e com a natureza; relação que a paisagem exprime concretamente". O sentido da relação tanto indica os diferentes significados estabelecidos nessa interação sociedade (cultura), natureza e espaço como também a lógica da organização social do espaço, em que aparece a estrutura do pensamento que orienta a produção material e imaterial das localidades. A produção imaterial se refere ao conjunto de significados, valores, ideias, conceitos, crenças, comportamentos, atitudes, manifestações artísticas, emoções, impressões e sensações diante da vida, da realidade - que tem nos objetos (corpos) a possibilidade de realização, de expressão. E os objetos apenas existem na medida em que são essa possibilidade de realização. Com isso, se quer chamar a atenção para uma das condições de existência das coisas no mundo, o simbólico refere-se aos diversos níveis de significação em que os espaço e suas relações se inserem.

É nesse contexto que Berque valoriza a paisagem, na medida em que exprime concreta e abstratamente a lógica mencionada acima, ou seja, o sentido da relação da sociedade com o espaço e com a de seu aparecer. As coisas se tornam existentes, para a humanidade, quando elas constituem objetos e ideias, significantes e significados, segundo o viés da semiótica. A materialidade da vida não é descartada. Muito pelo contrário, ela é valorizada, pois a existência humana exige espacialidades que abrigam as suas produções materiais e nãomateriais. A sociedade interage com a natureza e com o espaço por meio da cultura, sendo, simultaneamente, ativa e passiva.

Pelo exposto acima, fica evidente que o conceito operacional de cultura adotado nesta análise é aquele em que a mesma é entendida como o conjunto de formas simbólicas espaciais, onde os significados desempenham $\circ$ papel (regulador) de elaborar e de reelaborar todas as esferas da vida $^{3}$. As formas simbólicas têm o potencial de significar e de ressignificar o espaço, a natureza, as relações sociais, na medida em que

natureza. Daí advém a delimitação conceitual da paisagem como marca-matriz.

Ainda segundo Berque, a paisagem enquanto marca pode ser descrita e inventariada, indicando, desse modo, uma 
análise morfológica das localidades - por meio da qual se busca compreender a interação das formas entre si e entre as formas e suas funções. Essa análise tem como ponto de partida a paisagem como dado perceptível, sendo que a sua explicação extrapola o domínio do percebido; pois a função de uma forma, diz Berque, se define enquanto uma abstração, que varia conforme as escalas espacial e temporal de análise dos fenômenos, chamando a atenção para as ordens de grandeza não perceptíveis pelo homem. Neste sentido, a paisagem se presta tanto a uma análise objetiva quanto subjetiva. Este último caráter é assinalado pelo fato de existir primeiro em sua relação com um sujeito coletivo, na qual a sociedade a produz, reproduz e transforma em função de uma certa lógica. Contudo, não é suficiente determinar ou explicar o que produziu a paisagem enquanto objeto. Assim, segundo Berque (1983, p. 33),

É preciso compreender a paisagem enquanto marca, de uma parte, ela é vista por um olhar, apreendida por uma consciência, valorizada por uma experiência, julgada (e eventualmente produzida) por uma estética e um moral, gerada por uma política, etc.; e, de outra parte, enquanto matriz, quer dizer enquanto ela determina, de volta, este olhar, esta consciência, esta estética e esta moral, esta política, etc.

Desse modo, enquanto matriz, a paisagem determina $\bigcirc$ esquema de percepção (modos de ver), concepção e ação (práticas espaciais, como, por exemplo, as variadas formas de jardins) de uma determinada sociedade sobre o espaço e a natureza, em um tempo também específico. $E$ a cultura fornece os mecanismos para que esse esquema funcione. E enquanto marca "aparência", morfologia que exprime esse esquema de percepção, concepção e ação dos grupos sociais e dos indivíduos do/sobre o mundo -, assinala os referenciais que se tornam potência de possibilidades de reconhecimento das formas que designam experiências do mundo, assim, modelando a "experiência vida". Dessa maneira, para cada tempo e localidade distintos, uma espacialidade, um sentido, uma ordem do mundo é estabelecida.

Para Berque a definição dessa lógica é necessária para a compreensão do sentido da paisagem e do sentido da existência humana na Terra, uma vez que, desse modo, 
tal procedimento constitui o ponto de vista cultural.

É na condição de fazedor de paisagens e construtor de um imaginário social e geográfico da cidade do Rio de Janeiro que situamos Leandro Joaquim, emprestando o pincel para uma configuração da natureza e da cidade no Rio de Janeiro do Setecentos. Nesse período, surgem os primeiros contornos e preocupações com a afirmação de uma identidade nacional, que exigiu desse artista transformar o disforme caracterizado pela imensa diversidade da natureza e do mundo social - em algo com fisionomia mais definida.

A pintura traz uma intenção. $\bigcirc$ artista não é neutro. Leandro Joaquim é um pintor de paisagens. Pode não ter uma técnica tão apurada, contudo, o que a impressão de seus painéis mostra é a figuração da natureza e da cidade do Rio de Janeiro - uma paisagem carioca - em uma época em que esse tema não constituía uma preocupação por terras tupiniquins. Há ainda a presença forte de uma certa narrativa histórica em suas imagens. Contudo o que sobressai é o entorno que envolve a vida cotidiana dos personagens representados. De um lado, esses elementos são constitutivos e transformadores da paisagem. E de outro, o ambiente os constitui: natureza e cidade. Sem a ambiência que os envolve, a existência dos personagens enquanto representantes de grupos sociais não teria sentido.

A pintura coloca a questão sobre os diversos modos de ver e o que se ver. Afirma-se enquanto uma janela aberta para o mundo, reflexo das experiências humanas.

Leandro Joaquim sofre a influência das estampas e gravuras que vinham da Metrópole, marcadas pelo estilo barrocorococó ${ }^{4}$. Contudo, sua obra subverte essa ordem estilística ao fazer uso da imaginação e da criatividade que transformam a realidade por ele percebida. Constroi-se um mundo imaginário que, contudo, está muito próximo do real que se insere na ordem da verossimilhança - retomando um conceito de Aristóteles, na Poética, o que significa dizer que não é pelo critério de verdade que dá a constituição do mundo, das coisas, mas do possível e necessário que são regidos por uma coerência interna aos eventos.

A obra de Leandro Joaquim é portadora de um projeto de identidade local e nacional. $O$ artista fluminense coloca em questão a formação de um pensamento sobre nós mesmos, sobre a nossa inserção e condição no mundo, que é o "Brasil" e a Europa, o Mesmo e o Outro. Ele é, de certo modo, um dos primeiros a escrever e representar o projeto de uma nação. A pintura evoca a possibilidade de criar 0 
movimento de superposição de tempo e espaço, história e geografia, afirmando uma imaginação geográfica de cunho nacional, engendrando a construção de um modelo de interpretação e produção do mundo real e fictício próprio. A imaginação é uma fábrica que produz ideias, valores, objetos, coisas artista possui elementos ficcionais, dissimulações, que se transformam numa espécie de ensaio para realidades ainda não instauradas, engendrando a sua produção enquanto signo e preparação de edifica os primeiros caminhos em direção à formação de uma identidade local.

A narrativa é, diz Santos (1993), construída a partir da observação da natureza, percebida pela artista como manifestação da vida natural e do mundo social. $\bigcirc$ vínculo entre natureza e sociedade constitui o elemento de origem e fundante de uma identidade territorial. E a paisagem é por excelência a manifestação material e simbólica desse vínculo.

A preocupação do artista fluminense em descrever em suas pinturas a cor local, a natureza e a vida social "carioca" insinua o desejo de construção de uma unidade socioterritorial. Amandio dos Santos ressalta esse caráter da pintura de Leandro Joaquim, na qual é desvelado um emergente nacionalismo, até então impensado. Pela que podem vir ou não a habitar o mundo natural e social. Nas pinturas de Leandro Joaquim distintas trajetórias coexistem.

Para Santos (1993), a obra de Leandro Joaquim resulta da combinação entre o real, a ficção e o imaginário. A realidade vivenciada pelo um imaginário para receber o que está sendo anunciado. Assim, a aliança entre real, fictício e imaginário forma o que chamamos de realidade e primeira vez a pintura, no Brasil, torna-se um meio de expressão de nacionalidade, do desejo de afirmação de uma identidade local. Com isso, o que está em jogo é a elaboração da imagem de um povo espacializado. Pessoas e lugares passam a se autorreferenciarem. A condensação dessa ideia é manifesta na paisagem, que coloca a relação entre cultura e natureza, história e geografia, povo e lugar como pares indissociáveis para a construção visual e espacial da realidade.

Nesse sentido, podemos afirmar que a arte possui caráter pedagógico. Educa e forma um povo por meio de seus códigos artísticos, da linguagem e mensagens veículadas pelas obras de arte.

Seguindo essa reflexão, em nosso pensar geográfico, podemos afirmar que a 
representação fornece alguns indícios da parcela de ficção que compõe o real e do realismo das imagens que dele construímos. As imagens têm o poder de solicitar a presença de objetos e coisas ausentes. Muitas vezes essas imagens são tão fortes, que custa-nos crer no que nossos olhos veem.

Poderíamos afirmar que as experiências humanas do mundo, em parte, são invenções, construções, que fazem ou fariam parte do estoque de elementos visuais, pictóricos, escultóricos ou arquitetônicos, que representariam a cor local de um certo Rio de Janeiro, do estoque de aquisições culturais e cognitivas necessárias para a afirmação de uma nova espacialidade. Espacialidade essa que é abrigo de um novo modo de vida, que atribui um outro significado à cidade do Rio de Janeiro. Assim, há um Rio de Janeiro que se desenha, em parte, por meio da iconografia de Leandro Joaquim.

\section{CONSIDERAÇÕES FINAIS}

Se o espaço for considerado como um produto de interrelações, como sugere Massey (2008), como uma multiplicidade e como sempre em processo, inacabado, passamos a vê-lo como algo vivo, que interage com os diversos fenômenos e trajetórias históricas que se desenvolvem na superfície terrestre; tão dinâmico e dotado de uma mobilidade tão intensa quanto o tempo.

Pensar o espaço para além de sua condição de extensão, de suporte para os fenômenos e acontecimentos, conduz-nos a considerá-lo como uma entidade relacional que torna possível encontros de distintas trajetórias. Povos que estabelecem um conjunto de relações com a natureza e com o espaço, que confere a cada um deles uma identidade e cultura próprias.

Um das maneiras de conceber e habitar o espaço é por meio da imaginação. Para pensar e elaborar concepções sobre o espaço, ou qualquer outra entidade, faz-se necessário que construamos imagens sobre o mesmo. Quando há um imaginário sobre uma determinada entidade geográfica, entram em jogo os mecanismos para que a mesma ganhe materialidade, encarne, passe a existir para nós. Com isso, queremos afirmar que as coisas só passam a existir quando elas já habitam a nossa imaginação e se traduzem em uma linguagem - verbal ou não-verbal. E de acordo com o modo como imaginamos o espaço, as práticas sociais, políiticas, culturais, econômicas são diferenciadas. Desse movimento surgem distintas espacialidadades.

Ao questionar a noção de espaço, Doreen Massey (2008) propõe que 0 
pensemos como um encontro de histórias, que resultaria na construção de novas imaginações de tempo e de espaço. $\mathrm{Na}$ tentativa de refletir nova concepção de tempo e de espaço, estamos cada vez mais inclinados a reconhecer que Leandro Joaquim encontrou na pintura esse lugar / espaço de encontro - de histórias, nos lembraria Massey -, mais do que suporte para um fazer, onde imaginação e real se combinam para traçar os contornos de novas espacialidades e novas temporalidades se fazem presentes.

Quando falamos em imaginação e imaginário, há um remetimento quase que automático à produção de imagens e, por conseguinte, de paisagens. $E$ ao nos reportarmos à paisagem nos deparamos com a sua articulação com a produção de significados do mundo por meio de formas que informam, significam e indicam outras coisas.

É por meio da paisagem que a natureza se mostra. E é justamente a natureza afastadas da representação da natureza enquanto experiência europeia da paisagem.

O mar e a montanha compõem um imaginário da cidade; são estabelecidos composição de uma paisagem urbana. Trata-se da definição dos contornos de uma paisagem carioca. que evidenciará a paisagem, enquanto visão parcial / fragmentada do mundo, mas que carrega em si uma totalidade.

A encenação da vida, existente ou não, que coloca em questão a incorporação de modos de ser no mundo e modos de lidar com o desafio que a realidade do espaço projeta, pode ser expressa por meio de uma paisagem, por essa visão das partes em conjunto.

Nesse sentido, observamos que as obras de Leandro Joaquim colocam em evidência uma certa imaginação geográfica e a tentativa de suspender e eternizar - fixar uma espacialidade e arremessá-la para o futuro.

A natureza nas pinturas de Leandro Joaquim aparece como referência à imensidão e à diversidade e apresenta como principais signos o mar e a montanha. Essas características foram

como signos da cidade. As grandes edificações também aparecem como signo que identifica a cidade. A combinação desses elementos resulta na

Mar e montanha ainda hoje figuram como símbolos da cidade - que se espraiou sobre e entre eles. Como pensar a cidade carioca distante dessa paisagem? Como 
pensar sua gente fora desse pintura? A questão é que não pensamos. Não concebemos a cidade e seus habitantes fora dessa moldura, dessa janela que nos abre para o mundo, que nos coloca em contato com, que nos coloca em relação, que nos situa como seres relacionais.

É com a aparição da paisagem que o espaço se torna personagem importante da história dos homens, de suas trajetórias. Antes o senhor dos homens e de suas vidas era exclusivamente o tempo - o deus grego Hermes: o devorador e transformar de vidas. O espaço, passivamente, acolhia as metamorfoses fabricadas pelo tempo. Com a paisagem, além do tempo, além do homem, há um terceiro que participa da produção de mundos, por também se constituir enquanto relação necessária à existência da vida humana na Terra: o espaço, transfigurado em território.

Esse olhar renovado sobre o espaço/território que atinge a contemporaneidade faz com que as paisagens sejam revisitadas e ressignificadas. E o mesmo se estende à iconografia que a fixou no tempo e no espaço. É nesse contexto em que a obra de Leandro Joaquim transforma-se em um objeto de estudo extremamente instigante e relevante para a descoberta de novas geografias imaginativas.
NOTAS

${ }^{1}$ DELEUZE, Gilles. Proust e os signos. Rio de Janeiro: Forense Universitária, 1987, p. 43.

${ }^{2}$ C.f. CAUQUELIN, Anne. A invenção da paisagem. São Paulo: Martins Fontes, 2007, p. 137.

${ }^{3}$ Cf. CORRÊA, R. L; ROSENDAHL, Zeny. "A Geografia Cultural Brasileira: uma avaliação preliminar". Revista da ANPEGE, V. 4, P. 89-108, 2008.

${ }^{4} \mathrm{O}$ estilo barroco- rococó tem como principais traços a preocupação com os detalhes, adornos, luminosidade, elegância, refinamento e um certo realismo - observado no caráter descritivo das obras.

REFERENCIAS BIBLIOGRAFICAS

BERQUE, Augustin. Le sauvage et l'artifice. Le japanais devant la nature. Paris: Gallimard, 1996. 314p.

Les raisons du paysage. De la Chine Antique aux environnements de synthèse. Paris: Éditions Hazan, 1996.

Médiance. De milieux en paysages. Paris: Reclus, 1990

. "Paysage-empreinte, paysage-matrice. Eléments de problématique pour une Géographie Culturelle". L'Espace Géographique, 13 (1), 1984.

BESSE, Jean-Marc. Ver a Terra. Seis ensaios sobre a paisagem e a geografia. São Paulo: Perspectiva, 2006.

BUDDEMEIER, Heinz. Midia e violência. São Paulo: Antroposófica e Aliança, 2007.

CLAVAL, Paul. A geografia cultural. Florianópolis: Editora da UFSC, 1999

CAUQUELIN, Anne. A invenção da paisagem. São Paulo: Martins Fontes, 2007

CORRÊA, R. L; ROSENDAHL, Zeny. "A Geografia Cultural Brasileira: uma avaliação preliminar". Revista da ANPEGE, $\vee$. 4, P.89-108, 2008.

COSGROVE, Denis. A geografia está em toda parte: cultura e simbolismo nas paisagens humanas. In: CORRÊA, Roberto 
Lobato; ROSENDHAL, Zeny. Paisagem, tempo e cultura. Rio de Janeiro: EdUERJ, 1998, p. 92-121,.

Worlds of meaning: Cultural Geography and the imagination. In: FOOTE, Kenneth E. Re-reading the Cultural Geography. Austin: University of Texas, p. 387-395, 1994.

COSGROVE, Denis \& DANIELS, Stephen. The iconography of landscape. Cambridge: Cambridge University Press, 1988.

DELEUZE, Gilles. Proust e os signos. Rio de Janeiro: Forense Universitária, 1987, p. 43.

FERREZ, Gilberto. As primeiras telas paisagísticas da cidade. Revista do Patrimônio Histórico e Artístico Nacional. Rio de Janeiro: Ministério da Educação e Cultura, n. 17, p. 219-237, 1969.

FOUCAULT, Michel. As palavras e as coisas: uma arqueologia das ciências humanas. Tradução de Salma Tannus Muchail. 9 ed. São Paulo: Martins Fontes, 2007.

MASSEY, Doreen. Pelo espaço: uma nova política da espacialidade. Tradução de Hilda Pareto Maciel e Rogério Haesbaert. Rio de Janeiro: Bertrand Brasil, 2008.

edição 1925).
PANOFSKY. Erwin. Significado nas artes visuais. Tradução de Maria Clara F. Kneese e J. Guinsburg. 3 ed. São Paulo: Perspectiva, 2007. 439 p.

PEREIRA, Margareth da Silva. "Corpos escritos - paisagem, memória e monumento: visões da identidade carioca". In: FERREIRA, Glória/VENÂNCIO FILHO, Paulo (orgs.). Arte \& Ensaio, Rio de Janeiro, UFRJ, n. 7, p. 99-113, 2000.

ROGER, Alain. Le paysage occidental: retrospective et prospective. Le Débat, 65, 1991.

SANTOS, Amandio Miguel dos. "Os painéis elípticos de Leandro Joaquim na pintura do Rio de Janeiro setecentista". Gávea, Rio de Janeiro, v. 11, n. 11, p.131-151, abril 1994.

SANTOS, Amandio Miguel. "Solo és mãe gentil". A questão da pintura de "paisagem: caráter e natureza do Brasil" (Dissertação). Rio de Janeiro: UFRJ/EBA, 1993. 235 p.

SANTOS, Milton. A natureza do espaço. São Paulo: Hucitec, 1996.

SAUER, C.O. The morphology of landscape. In: LEIGHLY, John,. A selection from the writings of Carl Ortwin Saver. Berkeley: University of California Press, $1963 \quad\left(1^{\text {a }}\right.$

ABSTRACT: THIS PAPER DEALS WITH ISSUES RELATED TO THE REPRESENTATION OF LANDSCAPE PAINTING AS A MEDIATED EXPERIENCE OF SPATIAL REALITIES. THE LANDSCAPE APPEARS AS PERCEPTION OF THE AREA, USHERING IN A NEW WAY OF SHAPING AND INTERPRETING THE WORLD: ANOTHER LOOK. EXPERIENCE LANDSCAPE REFERS TO THE APPREHENSION OF THE WORLD AS A CULTURAL CONSTRUCT. THUS, THE VISION OF THE TERRITORY IS INTRINSICALLY RELATED TO AN ORGANIZATION OF THE VISIBLE, WHICH IS ASSIGNED A CERTAIN MEANING. IN THIS CONTEXT, IT WAS A JOURNEY MARKED THE EXPERIENCE OF LANDSCAPE IN ART AND GEOGRAPHY, WHICH GIVES AN UNDERSTANDING OF THE VISIBLE WORLD IN ITS VISUAL FORM AND IN THE CONTEXT OF LANGUAGE. THESE QUESTIONS AND DIALOGUE WITH THE PAINTINGS PLACEMENTS LEANDRO JOAQUIM, RIO DE JANEIRO ARTIST OF THE EIGHTEENTH CENTURY.

KEYWORDS: LANDSCAPE, REPRESENTATION, TERRITORY, IMAGE, LEANDRO JOAQUIM 